\title{
Tumor location of the central and nipple portion is associated with impaired survival for women with breast cancer
}

This article was published in the following Dove Medical Press journal: Cancer Management and Research

Fei Jil,*

Wei-Kai Xiao 2,*

Ci-Qiu Yangl,*

Mei Yang'

Liu-Lu Zhang'

Hong-Fei Gao'

Yu-Feng Lin'

Teng Zhu'

Min-Yi Cheng'

Wei-Ping Li'

Wei-Jun Pan'

Xiao-Sheng Zhuang'

Kun Wang'

'Department of Breast Cancer,

Cancer Center, Guangdong Provincial

People's Hospital, Guangdong

Academy of Medical Sciences,

Guangzhou 5I0080, P. R. China;

${ }^{2}$ Department of Breast Oncology, Sun

Yat-sen University Cancer Center,

State Key Laboratory of Oncology in

South China, Collaborative Innovation

Center for Cancer Medicine,

Guangzhou 5I0060, P.R. China

*These authors contributed equally to this work

Correspondence: Kun Wang

Department of Breast Cancer, Cancer

Center, Guangdong Provincial People's

Hospital, Guangdong Academy of Medical

Sciences, No. 106 Zhongshan Second

Road, Guangzhou 510080 , P. R. China

Tel +862081884713 ext 80420

Email gzwangkun@I26.com
Background: Tumor location in the breast varies, with the highest frequency in the upper outer quadrant and lowest frequency in the lower inner quadrant. Nevertheless, tumors in the central and nipple portion (TCNP) are poorly studied types of breast cancer; therefore, we aimed to clarify the clinicopathological characteristics and prognostic features of TCNP.

Methods: Using the Surveillance, Epidemiology, and End Results database, we identifed 105,037 patients diagnosed with tumor in the breast peripheral quadrant (TBPQ) $(n=97,046)$ or TCNP $(n=7,991)$. The chi-squared test was used to compare categorical variables across TCNP and TBPQ. Cox proportional hazard models with hazard ratios were applied to estimate the factors associated with prognosis.

Results:The median follow-up was over 43 months. Compared with TBPQ, TCNP patients were signifcantly older (age $\geq 66$ years: $40.4 \%$ vs $34.1 \%, \mathrm{P}<0.001$ ), with larger tumor sizes ( $>20 \mathrm{~mm}$ size: $46.9 \%$ vs $37.3 \%, \mathrm{P}<0.001$ ), higher proportions of TNM stage II-III (18.6\% vs $9.9 \%, \mathrm{P}<0.001)$, and more mastectomies ( $58.1 \%$ vs $37.8 \%, \mathrm{P}<0.001)$. The breast cancer-specifc survival (BCSS)/overall survival (OS) rate was signifcantly worse for TCNP than for TBPQ. Multivariate Cox analysis showed a higher hazard ratios for TCNP over TBPQ (BCSS: hazard ratios $=1.160, \mathrm{P}=0.005$, 95\% $\mathrm{CI}$ : 1.046-1.287; OS: hazard ratios $=1.301, \mathrm{P}<0.001,95 \% \mathrm{CI}$ : 1.211-1.398). A subgroup analysis revealed inferior outcomes for TCNP in TNM stage II-III and breast subtype subgroup. Multivariate logistic regression indicated that TCNP was an independent contributing factor to LN metastasis.

Conclusions: TCNP was associated with older age, larger tumor size, higher TNM stage, and lymph node metastasis. Compared with TBPQ, TCNP had adverse impacts on BCSS and OS.

Keywords: tumor in the central and nipple portion, tumor in the breast peripheral quadrant, prognosis, lymph node metastasis

\section{Introduction}

Breast cancer is the most common malignancy in women and one of the three most common cancers worldwide. Although mortality from breast cancer in North America and the European Union has decreased, breast cancer remains the most common cause of death from cancer in less-developed countries and is second to lung cancer in more developed countries. ${ }^{1,2}$ Therefore, it is essential to find effective parameters to identify patients with poor survival and to support them with personalized therapy.

A number of pathological characteristics, including tumor size and grade, hormone receptor (HR) status, human epidermal growth factor receptor-2 (HER2), and lymph node (LN) status, have been identified, all of which are considered when predicting prognosis and determining the most effective treatment options. ${ }^{3-5}$ Furthermore, 
molecular tests have been developed that add prognostic value by determining intrinsic subtype, stratification of tumors into low or high grade, or predicting recurrence. ${ }^{6-9}$ Despite these factors and tests, predicting patient outcome is not truly enough, as patients with similar pathological characteristics treated with identical regimens often exhibit highly variable clinical outcomes, indicating that additional prognostic factors are still need to be identified to improve patient stratification.

Tumor location in the breast has been reported as an independent prognostic factor. Tumors in the upper outer quadrant (UOQ) are the most frequent site of tumor location. They are associated with better survival compared with other quadrants; ${ }^{10,11}$ survival for non-UOQ tumors such as lower inner quadrant (LIQ) or medial regions have demonstrated lower survival. ${ }^{12-17}$ Axillary LN metastasis has also been suggested to be significantly lower in the upper inner quadrant (UIQ, 20.6\%) compared with all other quadrants $(33.2 \%) .{ }^{18}$ Nevertheless, studies regarding tumor in the central and nipple portion (TCNP) of the breast are discordant. One study suggested that breast cancer located closer to the nipple had a higher incidence of metastases to axillary LNs, ${ }^{19}$ while another demonstrated that there was no evidence that correlated intramammary tumor proximity to the nipple with the presence of axillary LN metastasis. ${ }^{20}$ Furthermore, the clinicopathological characteristics and the effect of TCNP on survival have still not been deeply explored.

Therefore, the aim of this study was to investigate the clinicopathological characteristics of TCNP and to clarify their prognostic value using a population-based database.

\section{Materials and methods Database}

We used the Surveillance, Epidemiology, and End Results (SEER) database (November 2017 submission), a National Cancer Institute-sponsored program, and obtained data from 18 population-based registries with the SEER * Stat software, version 8.3.4 (http://seer.cancer.gov/about/).

\section{Study population}

We derived a dataset of female breast cancer patients diagnosed from 2010 to 2013, for the reason of known HER2 status and follow-up time. The inclusion criteria were as follows: females aged over 18 years old; American Joint Committee on Cancer stages (the seventh AJCC System) TNM stage I-III; ${ }^{21,22}$ unilateral breast cancer; breast cancer as the first and only cancer diagnosis; TCNP or tumor in the breast peripheral quadrant (TBPQ) (including UOQ, UIQ, lower outer quadrant, LIQ, but overlapping sites were excepted); diagnosis not obtained from a death certificate or autopsy; pathologic confirmation of breast cancer; known tumor differentiation status (histological score); ${ }^{.23-25}$ known HR and HER2 status; ${ }^{26-28}$ known tumor size and LN status; known surgery type; known radiation/chemotherapy; and active follow-up. Patients with incomplete information were excluded. In total, 105,037 patients were included, including 7,991 TCNP (7.60\%) and 97,046 TBPQ patients (92.40\%).

\section{Ethics statement}

This study was approved by an independent ethical institutional review board at Guangdong Provincial People's Hospital and was carried out in accordance with the principles of the Declaration of Helsinki. The data released by the SEER database were publicly available and do not require patient's informed consent.

\section{Statistical analysis}

Statistical analysis was performed using SPSS software for Windows version 25.0 (SPSS Inc., Chicago, IL, USA). The chi-squared test was used to compare categorical variables across TCNP and TBPQ. Breast cancer-specific survival (BCSS) was defined as the survival time from the diagnosis date of breast cancer to the date of death caused by breast cancer, and the overall survival (OS) was defined as the time from the diagnosis date of breast cancer to the date of death from any cause. Kaplan-Meier curves, competing risks analysis (for BCSS), and log-rank tests (for OS) were generated to determine differences in the survival analyses. In addition, Cox proportional hazard models with hazard ratios were applied to estimate the factors associated with prognosis. A 1:1 paired match, by the propensity score matching (PSM) method, was also carried out to balance the impact of the baseline. Logistic regression was utilized to present the relationship between the tumor location and axillary LN metastasis. Two-sided $P<0.05$ was considered statistically significant, and reported $P$-values were not corrected for multiple testing.

\section{Results}

\section{Demographic and clinical characteristics of TCNP}

We first summarized the demographic and clinical characteristics of all 105,037 patients (Table 1). The median follow-up was over 43 months. Compared with the TBPQ patients, TCNP patients were significantly older (age $\geq 66$ years: $40.4 \%$ vs $34.1 \%, P<0.001$ ); they had a larger tumor size ( $>20 \mathrm{~mm}$ size: $46.9 \%$ vs $37.3 \%, P<0.001)$ and higher TNM stage II-III $(18.6 \%$ vs $9.9 \%, P<0.001)$. More TCNP 
Table I Baseline characteristics of patients with TCNP or TBPQ from the SEER database 20I0-20I3

\begin{tabular}{|c|c|c|c|c|c|c|}
\hline \multirow[t]{2}{*}{ Variables } & \multicolumn{2}{|c|}{ Data before PSM } & \multirow[t]{2}{*}{$P$-value } & \multicolumn{2}{|c|}{ Data after PSM } & \multirow[t]{2}{*}{$P$-value } \\
\hline & $\begin{array}{l}\text { TCNP } \\
(7,991)\end{array}$ & $\begin{array}{l}\text { TBPQ } \\
(97,046)\end{array}$ & & $\begin{array}{l}\text { TCNP } \\
(7,991)\end{array}$ & $\begin{array}{l}\text { TBPQ } \\
(7,991)\end{array}$ & \\
\hline Age (years), \% & & & $<0.001$ & & & 0.945 \\
\hline $18-45$ & 11.0 & 14.0 & & 11.0 & 11.0 & \\
\hline $46-55$ & 21.3 & 24.4 & & 21.3 & 21.1 & \\
\hline $56-65$ & 27.3 & 27.5 & & 27.3 & 27.8 & \\
\hline $66-79$ & 28.5 & 26.5 & & 28.5 & 28.5 & \\
\hline$>80$ & 11.9 & 7.6 & & 11.9 & 11.6 & \\
\hline Race, \% & & & $<0.001$ & & & 0.087 \\
\hline White & 79.9 & 79.5 & & 79.9 & 81.2 & \\
\hline Black & 9.2 & 10.8 & & 9.2 & 9.1 & \\
\hline Others & 10.9 & 9.7 & & 10.9 & 9.7 & \\
\hline Marital status, $\%$ & & & 0.744 & & & 0.929 \\
\hline Married & 81.3 & 81.0 & & 81.5 & 81.3 & \\
\hline Not married & 18.7 & 19.0 & & 18.5 & 18.7 & \\
\hline Laterality, \% & & & 0.576 & & & 0.962 \\
\hline Left & 51.3 & 50.9 & & 51.3 & 51.3 & \\
\hline Right & 48.7 & 49.1 & & 48.7 & 48.7 & \\
\hline Histology, \% & & & $<0.001$ & & & 0.617 \\
\hline IDC & 70.8 & 77.1 & & 70.8 & 71.3 & \\
\hline ILC & 10.4 & 8.4 & & 10.4 & 10.5 & \\
\hline Others & 18.8 & 14.5 & & 18.8 & 18.2 & \\
\hline Tumor differentiation, \% & & & $<0.001$ & & & 0.103 \\
\hline$|-| \mid$ & 67.1 & 65.3 & & 67.1 & 67.3 & \\
\hline III-IV & 32.9 & 34.7 & & 32.9 & 32.7 & \\
\hline TNM stage, $\%$ & & & $<0.001$ & & & $0.86 \mathrm{I}$ \\
\hline I & 81.4 & 90.1 & & 43.7 & 43.9 & \\
\hline II-III & 18.6 & 9.9 & & 56.3 & 56.1 & \\
\hline Tumor size (mm), \% & & & $<0.001$ & & & 0.111 \\
\hline $0-20$ & 53.1 & 62.7 & & 54.1 & 53.5 & \\
\hline $21-50$ & 35.1 & 31.1 & & 35.3 & 36.6 & \\
\hline$>50$ & 11.8 & 6.2 & & 10.6 & 9.9 & \\
\hline LN status, $\%$ & & & $<0.001$ & & & $0.87 I$ \\
\hline Negative & 61.3 & 72.2 & & 61.3 & 61.1 & \\
\hline Positive & 38.7 & 27.8 & & 38.7 & 38.9 & \\
\hline Breast subtype, \% & & & $<0.001$ & & & 0.174 \\
\hline $\mathrm{HER}^{-} / \mathrm{HR}^{+}$ & 76.0 & 74.0 & & 76.0 & 77.1 & \\
\hline $\mathrm{HER}^{+} / \mathrm{HR}^{+}$ & 10.8 & 9.7 & & 10.8 & 10.1 & \\
\hline $\mathrm{HER}^{+} / \mathrm{HR}^{-}$ & 4.9 & 4.0 & & 4.9 & 4.4 & \\
\hline Triple-negative & 8.3 & 12.3 & & 8.3 & 8.4 & \\
\hline Surgery, $\%$ & & & $<0.001$ & & & 0.873 \\
\hline Lumpectomy & 41.9 & 62.2 & & 41.9 & 41.8 & \\
\hline Mastectomy & 58.1 & 37.8 & & 58.1 & 58.2 & \\
\hline Radiation, \% & & & $<0.001$ & & & 0.419 \\
\hline Yes & 47.3 & 56.9 & & 47.3 & 47.5 & \\
\hline No/unknown & 52.7 & 43.1 & & 52.7 & 52.5 & \\
\hline Chemotherapy, \% & & & 0.233 & & & 0.987 \\
\hline Yes & 42.2 & 41.5 & & 42.2 & 42.2 & \\
\hline No/unknown & 57.8 & 58.5 & & 57.8 & 57.8 & \\
\hline
\end{tabular}

Abbreviations: HER2, human epidermal growth factor receptor-2; HR, hormone receptor; IDC, invasive ductal carcinoma; ILC, invasive lobular carcinoma; LN, lymph node; PSM, propensity score matching; SEER, Surveillance, Epidemiology, and End Results; TBPQ, tumor in the breast peripheral quadrant; TCNP, tumor in the central and nipple portion. 
patients underwent mastectomy (58.1\% vs 37.8\%, $P<0.001)$. Furthermore, TCNP had a significantly higher LN positivity rate $(\mathrm{LN}+: 38.7 \%$ vs $27.8 \%, P<0.001)$. These characteristics suggested that TCNP had a clinicopathological baseline distinct from that of TBPQ.

\section{Comparison of survival between TCNP and TBPQ}

To evaluate the BCSS and OS of TCNP and TBPQ, the Kaplan-Meier method was used. The 5-year BCSS rates of the patients with TCNP were significantly lower than those of the TBPQ population $(92.1 \%$ vs $94.9 \%, P<0.001)$ (Figure 1A). Furthermore, the 5-year OS rates of the patients with TCNP were markedly lower than those of the TBPQ population ( $84.8 \%$ vs $92.5 \%, P<0.001)$ (Figure 1B).

A

BCSS before PSM

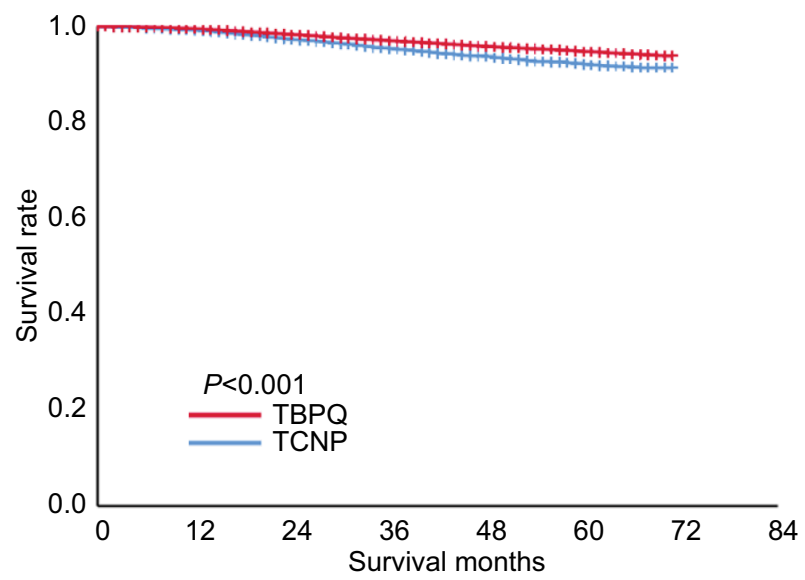

C

BCSS after PSM

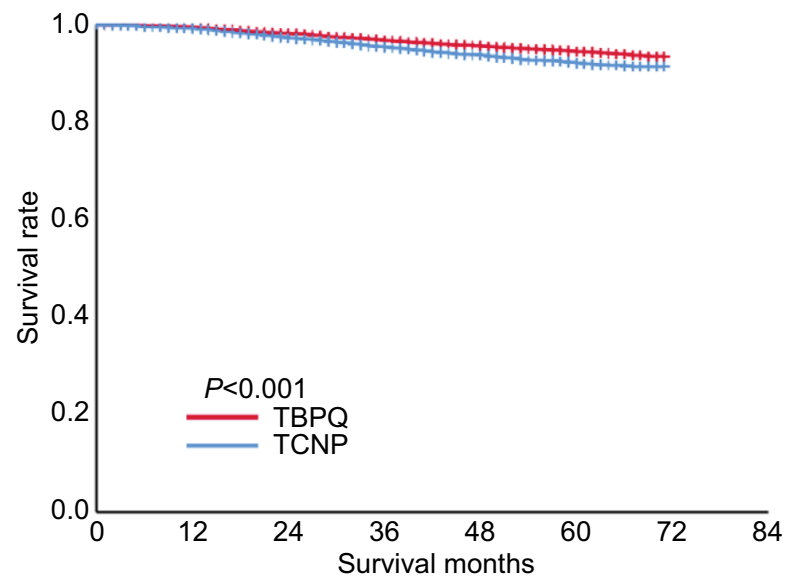

Because of the distinct clinicopathological baseline of TCNP, univariate and multivariate Cox proportional hazards models were used to balance the effect of factors.

Age, race, marital status, location of TCNP or TBPQ, tumor differentiation, TNM stage, tumor size, LN status, breast subtype, surgery type, radiation, and chemotherapy (all $P<0.001$ ) were responsible for BCSS. Similarly, the significant predictors of OS in patients were race, marital status, location of TCNP or TBPQ, TNM stage, tumor size, LN status, surgery type, and radiation (all $P<0.001$ ) (Table 2 ). After multivariate analysis, we found that race, marital status, location of TCNP or TBPQ, tumor differentiation, TNM stage, tumor size, LN status, breast subtype, surgery type, and radiation were significant independent predictors of BCSS (all $P<0.05$ ), while race, location of TCNP or TBPQ, tumor differentiation, TNM stage, tumor

B

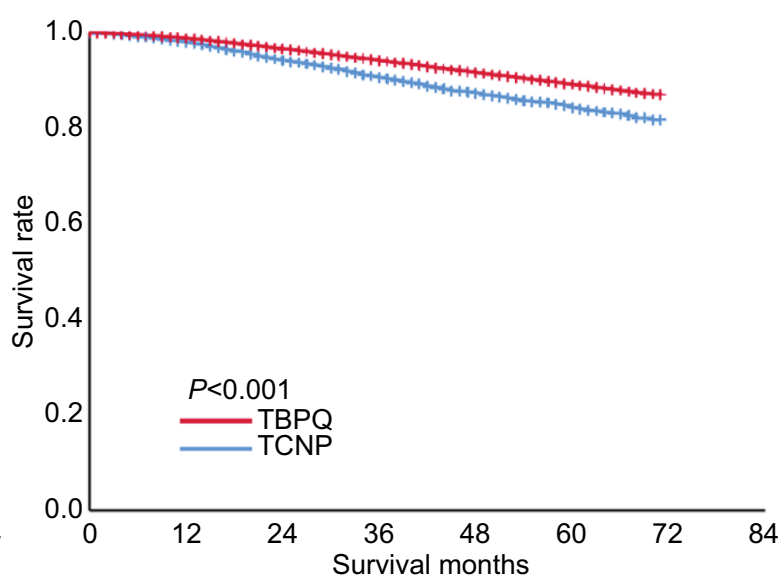

D

OS after PSM

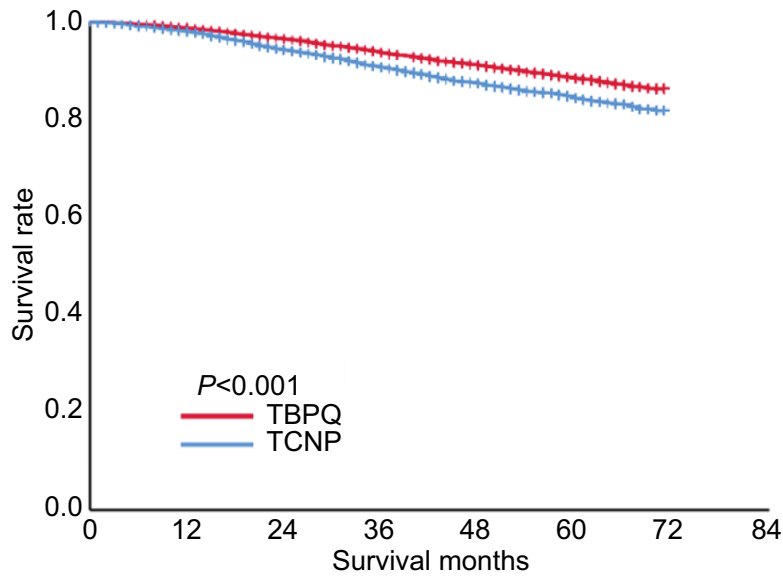

Figure I Relationship between TCNP/TBPQ and BCSS/OS of breast cancer patients.

Notes: (A) BCSS of patients with TCNP was significantly shorter than those with TBPQ, including BCSS after PSM (C). (B) OS of patients with TCNP was also markedly shorter than those with TBPQ, including BCSS after PSM (D).

Abbreviations: BCSS, breast cancer specific survival; OS, overall survival; PSM, propensity score matching; SEER, Surveillance, Epidemiology, and End Results; TBPQ, tumor in the breast peripheral quadrant; TCNP, tumor in the central and nipple portion. 
Table 2 Univariate Cox regression model analysis of BCSS and OS between TCNP and TBPQ

\begin{tabular}{|c|c|c|c|c|c|c|}
\hline \multirow[t]{2}{*}{ Variables } & \multicolumn{3}{|l|}{ BCSS } & \multicolumn{3}{|l|}{ OS } \\
\hline & Hazard ratios & $95 \% \mathrm{Cl}$ & $P$-value & Hazard ratios & $95 \% \mathrm{Cl}$ & $P$-value \\
\hline \multicolumn{7}{|l|}{ Age (years) } \\
\hline $18-45$ & \multicolumn{2}{|l|}{ Reference } & & \multicolumn{3}{|l|}{ Reference } \\
\hline $46-55$ & 0.729 & $0.660-0.805$ & $<0.001$ & 0.818 & $0.748-0.894$ & $<0.001$ \\
\hline $56-65$ & 0.660 & $0.598-0.729$ & $<0.001$ & 0.971 & $0.892-1.056$ & 0.490 \\
\hline $66-79$ & 0.732 & $0.664-0.808$ & $<0.001$ & 1.640 & $1.515-1.774$ & $<0.001$ \\
\hline$\geq 80$ & 1.685 & $1.5 \mathrm{II}-1.879$ & $<0.001$ & 5.433 & $5.017-5.884$ & $<0.001$ \\
\hline \multicolumn{7}{|l|}{ Race } \\
\hline White & \multicolumn{2}{|l|}{ Reference } & & \multicolumn{3}{|l|}{ Reference } \\
\hline Black & 1.908 & $1.763-2.064$ & $<0.001$ & 1.471 & $1.386-1.560$ & $<0.001$ \\
\hline Others & 0.690 & $0.606-0.787$ & $<0.001$ & 0.584 & $0.530-0.642$ & $<0.001$ \\
\hline \multicolumn{7}{|l|}{ Marital status } \\
\hline Married & \multicolumn{2}{|l|}{ Reference } & & \multicolumn{3}{|l|}{ Reference } \\
\hline Unmarried & 1.392 & $1.283-1.509$ & $<0.001$ & 1.122 & $1.056-1.192$ & $<0.001$ \\
\hline \multicolumn{7}{|l|}{ Location } \\
\hline TBPQ & \multicolumn{3}{|l|}{ Reference } & \multicolumn{3}{|l|}{ Reference } \\
\hline TCNP & 1.532 & $1.384-1.696$ & $<0.001$ & 1.522 & $1.418-1.634$ & $<0.001$ \\
\hline \multicolumn{7}{|l|}{ Laterality } \\
\hline Left & \multicolumn{2}{|l|}{ Reference } & & \multicolumn{3}{|l|}{ Reference } \\
\hline Right & 0.946 & $0.889-1.005$ & 0.074 & 0.971 & $0.931-1.013$ & 0.971 \\
\hline \multicolumn{7}{|l|}{ Histology } \\
\hline IDC & \multicolumn{2}{|l|}{ Reference } & & Reference & & \\
\hline ILC & 0.743 & $0.657-0.840$ & $<0.001$ & 0.960 & $0.889-1.073$ & 0.303 \\
\hline Others & 0.822 & $0.749-0.901$ & $<0.001$ & 0.978 & $0.921-1.039$ & 0.472 \\
\hline Tumor differe & & & & & & \\
\hline $\mathrm{I}-\mathrm{II}$ & Reference & & & Reference & & \\
\hline III-IV & 4.687 & $4.376-5.020$ & $<0.001$ & 2.155 & $2.062-2.253$ & $<0.001$ \\
\hline TNM stage & & & & & & \\
\hline 1 & Reference & & & Reference & & \\
\hline II-III & 7.225 & $6.625-7.879$ & $<0.001$ & 2.719 & $2.597-2.846$ & $<0.001$ \\
\hline Tumor size ( $r$ & & & & & & \\
\hline $0-20$ & Reference & & & Reference & & \\
\hline $21-50$ & 4.209 & $3.909-4.532$ & $<0.001$ & 2.361 & $2.255-2.472$ & $<0.001$ \\
\hline$>50$ & 10.965 & $10.032-11.983$ & $<0.001$ & 4.540 & $4.253-4.874$ & $<0.001$ \\
\hline LN status & & & & & & \\
\hline Negative & Reference & & & Reference & & \\
\hline Positive & 4.435 & $4.160-4.729$ & $<0.001$ & 2.139 & $2.050-2.232$ & $<0.001$ \\
\hline Breast subtyp & & & & & & \\
\hline HER2-//HR ${ }^{+}$ & Reference & & & Reference & & \\
\hline $\mathrm{HER}^{+} / \mathrm{HR}^{+}$ & 1.343 & $1.199-1.505$ & $<0.001$ & 1.018 & $0.941-1.101$ & 0.656 \\
\hline $\mathrm{HER}^{+} / \mathrm{HR}^{-}$ & 2.818 & $2.496-3.181$ & $<0.001$ & 1.606 & $1.460-1.767$ & $<0.001$ \\
\hline Triple-negative & 4.810 & $4.495-5.147$ & $<0.001$ & 2.557 & $2.430-2.690$ & $<0.001$ \\
\hline Surgery & & & & & & \\
\hline Lumpectomy & Reference & & & Reference & & \\
\hline Mastectomy & 2.671 & $2.507-2.846$ & & 1.759 & $1.686-1.836$ & $<0.001$ \\
\hline Radiation & & & & & & \\
\hline Yes & Reference & & & Reference & & \\
\hline No & 1.505 & $1.413-1.605$ & $<0.001$ & 1.861 & $1.780-1.946$ & $<0.001$ \\
\hline Chemotherap & & & & & & \\
\hline Yes & Reference & & & Reference & & \\
\hline No/unknown & 0.389 & $0.364-0.416$ & $<0.001$ & 0.984 & $0.94 I-I .029$ & 0.483 \\
\hline
\end{tabular}

Abbreviations: BCSS, breast cancer specific survival; HER2, human epidermal growth factor receptor-2; HR, hormone receptor; IDC, invasive ductal carcinoma; ILC, invasive lobular carcinoma; LN, lymph node; OS, overall survival; TBPQ, tumor in the breast peripheral quadrant; TCNP, tumor in the central and nipple portion. 
size, LN status, surgery type, and radiation were significant independent predictors of OS (all $P<0.05$ ). The tumor location of TCNP was confirmed as an independent risk factor over TBPQ in terms of both BCSS and OS (BCSS: hazard ratios $=1.160, P=0.005,95 \%$ CI: $1.046-1.287$; OS: hazard ratios $=1.301, P<0.001,95 \%$ CI: $1.211-1.398)$ (Table 3 ).

\section{Survival analysis in the matched group}

A 1:1 (TCNP/TBPQ) matched case-control analysis by PSM was performed to balance the baseline differences. In total, 7,991 patients were obtained for each location type. Ten factors were included in the PSM, including age, race, marital status, laterality, histology, tumor differentiation, TNM stage, tumor size, LN status, breast subtype, surgery type, radiation, and chemotherapy. No statistically significant differences were found in terms of the characteristics between the two groups (Table 1). The survival analysis of the matched groups, which was consistent with the entire cohort analysis, showed that TCNP presented a worse outcome for the BCSS (5-year BCSS: $92.1 \%$ vs $94.5 \%, P<0.001$ ) (Figure 1C) and a

Table 3 Multivariate Cox regression model analysis of the BCSS and OS between TCNP and TBPQ

\begin{tabular}{|c|c|c|c|c|c|c|}
\hline \multirow[t]{2}{*}{ Variables } & \multicolumn{3}{|l|}{ BCSS } & \multicolumn{3}{|l|}{ OS } \\
\hline & Hazard ratios & $95 \% \mathrm{Cl}$ & $P$-value & Hazard ratios & $95 \% \mathrm{Cl}$ & $P$-value \\
\hline \multicolumn{7}{|l|}{ Age (years) } \\
\hline $18-45$ & \multicolumn{3}{|l|}{ Reference } & & & \\
\hline $46-55$ & 1.045 & $0.942-1.160$ & 0.401 & & & \\
\hline $56-65$ & 1.173 & $1.056-1.302$ & 0.003 & & & \\
\hline $66-79$ & 1.609 & I.449-I.787 & $<0.001$ & & & \\
\hline$\geq 80$ & 3.521 & $3.130-3.960$ & $<0.001$ & & & \\
\hline \multicolumn{7}{|l|}{ Race } \\
\hline White & \multicolumn{3}{|l|}{ Reference } & \multicolumn{3}{|l|}{ Reference } \\
\hline Black & 1.260 & $\mathrm{I} .158-1.372$ & $<0.001$ & 1.207 & $1.134-1.285$ & $<0.001$ \\
\hline Others & 0.686 & $0.598-0.787$ & $<0.001$ & 0.543 & $0.491-0.600$ & $<0.001$ \\
\hline \multicolumn{7}{|l|}{ Marital status } \\
\hline Married & \multicolumn{3}{|l|}{ Reference } & & & \\
\hline Unmarried & 1.203 & $1.106-1.308$ & $<0.001$ & & & \\
\hline \multicolumn{7}{|l|}{ Location } \\
\hline TBPQ & \multicolumn{3}{|l|}{ Reference } & \multicolumn{3}{|l|}{ Reference } \\
\hline TCNP & 1.160 & $1.046-1.287$ & 0.005 & $\mathrm{I} .30 \mathrm{I}$ & $1.211-1.398$ & $<0.001$ \\
\hline \multicolumn{7}{|c|}{ Tumor differentiation } \\
\hline $\mathrm{I}-\mathrm{II}$ & \multicolumn{3}{|l|}{ Reference } & \multicolumn{3}{|l|}{ Reference } \\
\hline III-IV & 2.412 & $2.228-2.612$ & $<0.001$ & 1.652 & $1.578-1.730$ & $<0.001$ \\
\hline \multicolumn{7}{|l|}{ TNM stage } \\
\hline 1 & \multicolumn{3}{|l|}{ Reference } & \multicolumn{3}{|l|}{ Reference } \\
\hline II-III & 1.826 & $1.579-2.112$ & $<0.001$ & 1.109 & $1.004-1.224$ & 0.041 \\
\hline \multicolumn{7}{|c|}{ Tumor size $(\mathrm{mm})$} \\
\hline $0-20$ & \multicolumn{3}{|l|}{ Reference } & \multicolumn{3}{|l|}{ Reference } \\
\hline $21-50$ & 1.535 & $1.375-1.714$ & $<0.001$ & 1.643 & $|.507-| .79 \mid$ & $<0.001$ \\
\hline$>50$ & 3.187 & $2.818-3.604$ & $<0.001$ & 3.116 & $2.823-3.439$ & $<0.001$ \\
\hline \multicolumn{7}{|l|}{ LN status } \\
\hline Negative & \multicolumn{3}{|l|}{ Reference } & \multicolumn{3}{|l|}{ Reference } \\
\hline Positive & 2.474 & $2.283-2.68 \mathrm{I}$ & $<0.001$ & 1.509 & $1.427-1.595$ & $<0.001$ \\
\hline Breast subtyp & & & & & & \\
\hline $\mathrm{HER}^{-}-\mathrm{HR}^{+}$ & Reference & & & & & \\
\hline $\mathrm{HER}^{+} / \mathrm{HR}^{+}$ & 0.846 & $0.750-0.955$ & 0.007 & & & \\
\hline $\mathrm{HER}^{+} / \mathrm{HR}^{-}$ & 1.358 & $1.192-1.547$ & $<0.001$ & & & \\
\hline Triple-negative & 2.590 & $2.391-2.806$ & $<0.001$ & & & \\
\hline Surgery & & & & & & \\
\hline Lumpectomy & Reference & & & Reference & & \\
\hline Mastectomy & 1.271 & $1.179-1.370$ & $<0.001$ & 0.905 & $0.859-0.952$ & $<0.001$ \\
\hline Radiation & & & & & & \\
\hline Yes & Reference & & & Reference & & \\
\hline No/unknown & 1.326 & $1.237-1.421$ & $<0.001$ & 1.908 & $1.816-2.005$ & $<0.001$ \\
\hline
\end{tabular}

Abbreviations: BCSS, breast cancer specific survival; HER2, human epidermal growth factor receptor-2; HR, hormone receptor; LN, lymph node; OS, overall survival; TBPQ, tumor in the breast peripheral quadrant; TCNP, tumor in the central and nipple portion. 
statistically worse outcome for the OS (5-year OS: $84.3 \%$ vs $92.1 \%, P<0.001$ ) compared with TBPQ (Figure 1D).

\section{Survival analysis in various subgroups}

The analyses above verified that TCNP was an independent prognostic factor and significantly negatively correlated with BCSS and OS. We next assessed the prognostic value of TCNP compared with TBPQ in various subgroups. We found that TCNP was a worse prognostic indicator for
BCSS $(P<0.001)$ and OS $(P<0.001)$ in patients with TNM stage II-III (Figure 2A, B), and this poor prognostic value of BCSS and OS of TCNP also existed for patients with HER2 ${ }^{-} / \mathrm{HR}^{+}$(BCSS: $P=0.001$; OS: $P<0.001$ ) (Figure $3 \mathrm{~A}$, E), HER2 ${ }^{+} / \mathrm{HR}^{+}$(BCCS: $P<0.001$; OS: $P<0.001$ ) (Figure 3C, G), and triple-negative cancer (Figure 3D, H) (BCSS: $P<0.001$; OS: $P<0.001)$. Despite the fact that prognostic value of BCSS of TCNP in patients with $\mathrm{HER} 2^{+} / \mathrm{HR}^{-}$ showed no significance $(P=0.538)$, OS of TCNP in patients
A

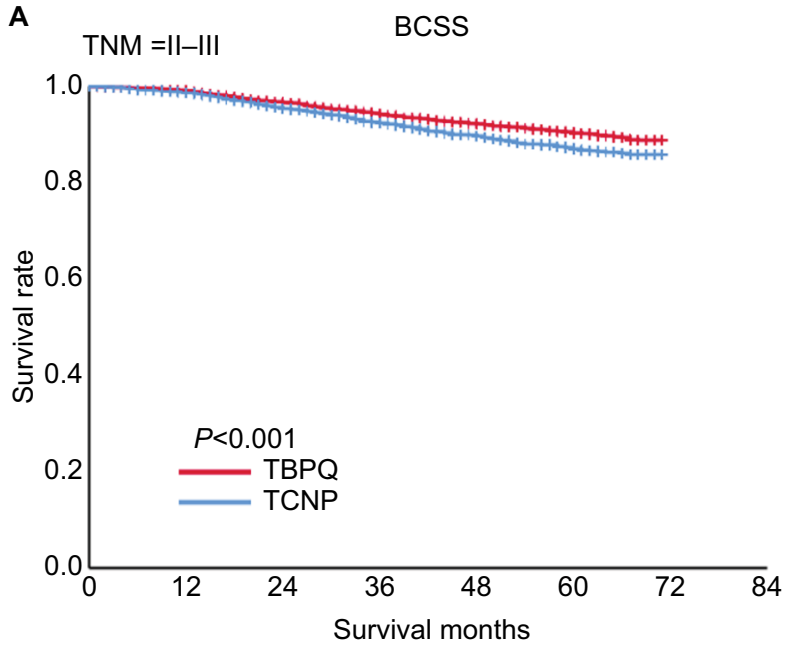

B

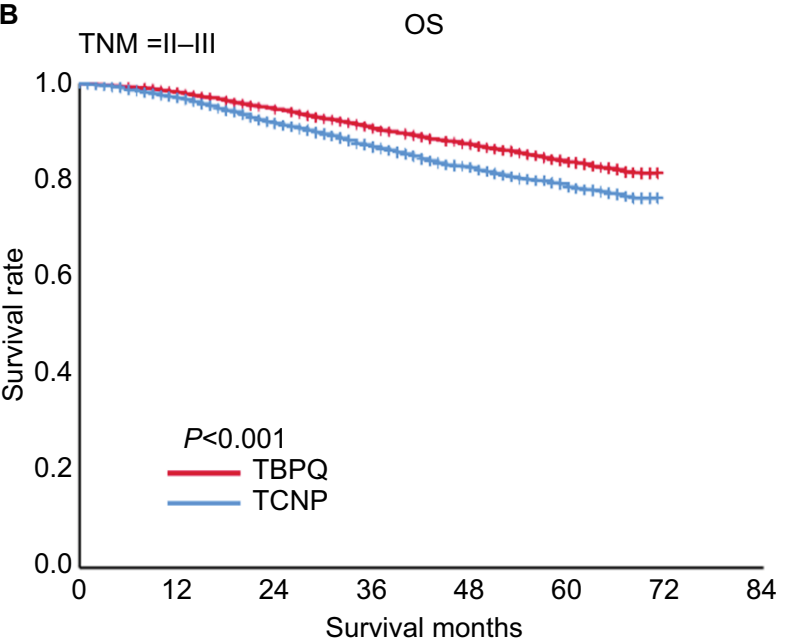

Figure 2 Kaplan-Meier survival curves of different breast cancer subgroups.

Note: TCNP significantly correlated with shorter BCSS and OS in subgroups with TNM stage II-III (A, B).

Abbreviations: BCSS, breast cancer specific survival; OS, overall survival; TBPQ, tumor in the breast peripheral quadrant; TCNP, tumor in the central and nipple portion.

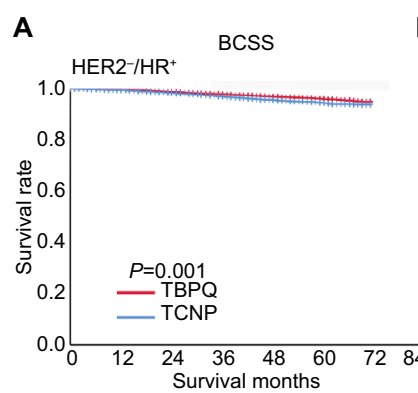

E

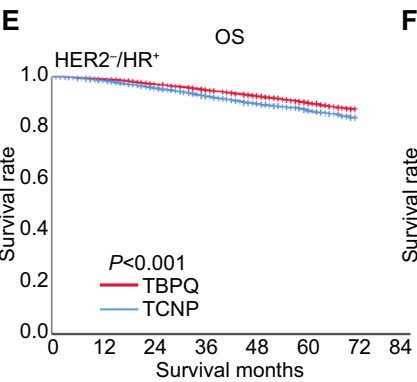

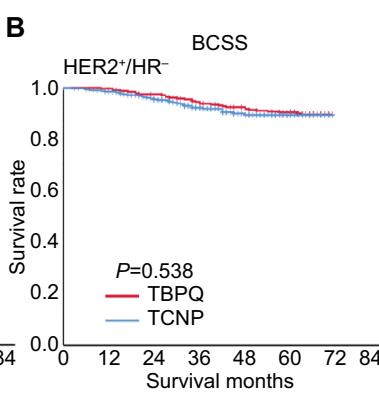

$\mathbf{F}$

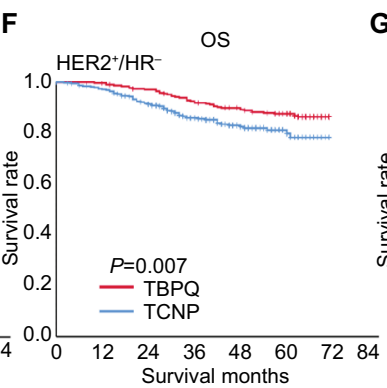

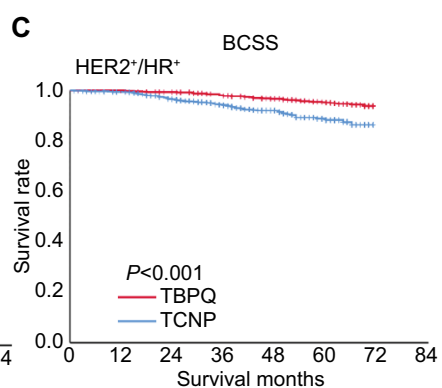

G

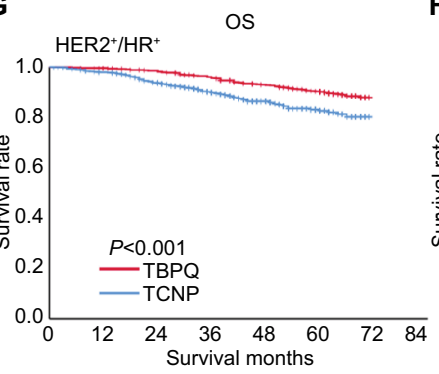

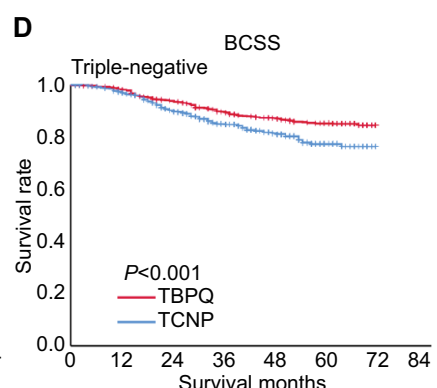

H

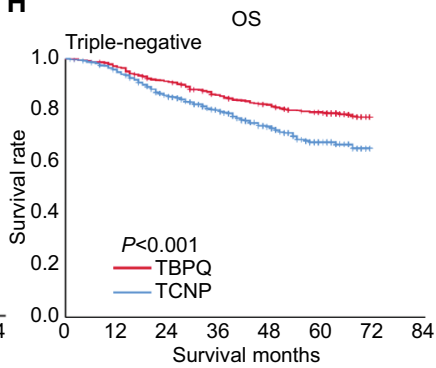

Figure 3 Kaplan-Meier survival curves of different breast cancer subgroups.

Note: TCNP significantly correlated with shorter BCSS and OS in subgroups with various breast subtypes $(\mathbf{A}-\mathbf{H})$.

Abbreviations: BCSS, breast cancer specific survival; HER2, human epidermal growth factor receptor-2; HR, hormone receptor; OS, overall survival; TBPQ, tumor in the breast peripheral quadrant; TCNP, tumor in the central and nipple portion. 
with $\mathrm{HER} 2^{+} / \mathrm{HR}^{-}$was significant $(P=0.007)$ (Figure $3 \mathrm{~B}, \mathrm{~F}$ and Table 4).

\section{TCNP related to $\mathrm{LN}$ metastases of breast cancer}

To clarify the reasons leading to poor prognosis of TCNP, we analyzed the relationship between TCNP and LN metastases of breast cancer. Variables that were significant $(P<0.001)$ in the univariate logistic analysis (age, race, tumor location, histology, tumor differentiation, TNM stage, tumor size, and breast subtype) were further included in the multivariate logistic regression analysis. TCNP was more likely to metastasize to $\mathrm{LNs}(\mathrm{OR}=3.903,95 \% \mathrm{CI}: 3.687-4.133, P<0.001)$ (Table 5). This result verified the linkage of TCNP and LN metastasis and may partially explain the worse outcome for TCNP.

\section{Discussion}

Determination of whether tumor location can be used prognostically is important in optimizing treatment. TCNP has a unique anatomical position, but its clinicopathological and survival characteristics are not well investigated. In this study, we showed that TCNP, compared with TBPQ, has distinct clinicopathological characteristics and worse survival.

First, we found that TCNP patients were mainly in an older age group (age $\geq 66$ years), with larger tumor sizes (>20 mm size) and higher TNM stages (II-III). This may because tumors within the central region are harder to detect for reasons of overpenetration of X-rays in the nipple-areolar complex and may reach a substantially larger size before being detected by imaging; ${ }^{29}$ therefore, TCNP relates to tumor burden and progression. By univariate analysis, we found many significant prognostic factors for BCSS or OS, including age, race, marital status, location of TCNP or TBPQ, tumor differentiation, TNM stage, tumor size, LN status, breast subtype, surgery type, radiation, and chemotherapy. After multivariate analysis, however, we discovered that only race, location of TCNP or TBPQ, tumor differentiation, TNM stage, tumor size, LN status, surgery type, and radiation were significant independent predictors of BCSS and OS. Tumor location of TCNP was finally confirmed as an independent risk factor over TBPQ for both BCSS and OS.

Through further analysis, we found that shorter survival of TCNP patients was detected in this study. The 1-, 3-, and 5 -year BCSS rates and OS rates of patients with TCNP were markedly lower than those of patients with TBPQ, including the survival analysis after PSM. The mechanisms may be the understaging of TCNP at diagnosis. Ansari et a ${ }^{19}$ reported that breast cancers located closer to the nipple have a higher incidence of metastases to axillary LN s. In our study, TCNP had a significantly higher LN positivity rate than TBPQ (LN+: $38.7 \%$ vs $27.8 \%, P<0.001$ ). We also conducted a multivariate logistic regression analysis that indicated that TCNP was an independent indicator for LN metastasis, and metastasis is the fundamental cause of higher mortality and poorer prognosis of patients who suffer from malignant tumors. Furthermore, the difficulty of mammographic detection and more frequent occurrence of

Table 4 BCSS rates, OS rates, and $P$-values for various subgroups

\begin{tabular}{|c|c|c|c|c|c|c|c|c|}
\hline \multirow[t]{2}{*}{ Groups } & \multicolumn{4}{|l|}{ BCSS } & \multicolumn{4}{|l|}{ OS } \\
\hline & I-year & 3-year & 5-year & $P$-value & I-year & 3-year & 5-year & $P$-value \\
\hline \multicolumn{9}{|c|}{ TNM II-III } \\
\hline TBPQ & $99.1 \%$ & $94.2 \%$ & $90.3 \%$ & $<0.001$ & $98.1 \%$ & $90.7 \%$ & $83.8 \%$ & $<0.001$ \\
\hline TCNP & $98.7 \%$ & $92.4 \%$ & $87.0 \%$ & & $97.0 \%$ & $86.9 \%$ & $78.6 \%$ & \\
\hline \multicolumn{9}{|c|}{${\text { HER2- } / \mathbf{H R}^{+}}^{+}$} \\
\hline TBPQ & $99.6 \%$ & $97.8 \%$ & $95.9 \%$ & 0.001 & $98.8 \%$ & $94.7 \%$ & $89.6 \%$ & $<0.001$ \\
\hline TCNP & $99.5 \%$ & $96.9 \%$ & $94.4 \%$ & & $98.3 \%$ & $92.3 \%$ & $86.7 \%$ & \\
\hline \multicolumn{9}{|c|}{ HER2 $^{+} / \mathrm{HR}^{+}$} \\
\hline $\begin{array}{l}\text { TBPQ } \\
\text { TCNP }\end{array}$ & $\begin{array}{l}100 \% \\
99.4 \%\end{array}$ & $\begin{array}{l}97.8 \% \\
94.2 \%\end{array}$ & $\begin{array}{l}95.2 \% \\
88.3 \%\end{array}$ & $<0.001$ & $\begin{array}{l}99.6 \% \\
97.9 \%\end{array}$ & $\begin{array}{l}95.6 \% \\
89.8 \%\end{array}$ & $\begin{array}{l}90.2 \% \\
82.6 \%\end{array}$ & $<0.001$ \\
\hline \multicolumn{9}{|c|}{ HER2 $^{+} / \mathrm{HR}^{-}$} \\
\hline $\begin{array}{l}\text { TBPQ } \\
\text { TCNP }\end{array}$ & $\begin{array}{l}99.0 \% \\
98.4 \%\end{array}$ & $\begin{array}{l}93.8 \% \\
92.2 \%\end{array}$ & $\begin{array}{l}90.4 \% \\
89.4 \%\end{array}$ & 0.538 & $\begin{array}{l}99.7 \% \\
97.2 \% \\
\end{array}$ & $\begin{array}{l}91.9 \% \\
85.6 \%\end{array}$ & $\begin{array}{l}87.6 \% \\
79.8 \%\end{array}$ & 0.007 \\
\hline \multicolumn{9}{|c|}{ Triple-negative } \\
\hline $\begin{array}{l}\text { TBPQ } \\
\text { TCNP }\end{array}$ & $\begin{array}{l}98.1 \% \\
96.9 \%\end{array}$ & $\begin{array}{l}89.4 \% \\
84.8 \%\end{array}$ & $\begin{array}{l}85.2 \% \\
77.3 \%\end{array}$ & $<0.001$ & $\begin{array}{l}96.7 \% \\
94.8 \%\end{array}$ & $\begin{array}{l}85.4 \% \\
79.5 \%\end{array}$ & $\begin{array}{l}79.0 \% \\
67.6 \%\end{array}$ & $<0.001$ \\
\hline
\end{tabular}

Abbreviations: BCSS, breast cancer specific survival; HER2, human epidermal growth factor receptor-2; HR, hormone receptor; OS, overall survival; TBPQ, tumor in the breast peripheral quadrant; TCNP, tumor in the central and nipple portion. 
Table 5 Univariate and multivariate logistic regression analysis on LN metastasis

\begin{tabular}{|c|c|c|c|c|c|c|}
\hline \multirow[t]{2}{*}{ Variables } & \multicolumn{3}{|c|}{ Univariate analysis } & \multicolumn{3}{|c|}{ Multivariate analysis } \\
\hline & OR & $95 \% \mathrm{Cl}$ & $P$-value & OR & $95 \% \mathrm{Cl}$ & $P$-value \\
\hline \multicolumn{7}{|l|}{ Age (years) } \\
\hline $18-45$ & \multicolumn{2}{|c|}{ Reference } & & \multicolumn{3}{|c|}{ Reference } \\
\hline $46-55$ & 0.486 & $0.465-0.507$ & $<0.001$ & 0.852 & $0.805-0.902$ & $<0.001$ \\
\hline $56-65$ & 0.360 & $0.345-0.375$ & $<0.001$ & 0.764 & $0.722-0.809$ & $<0.001$ \\
\hline $66-79$ & 0.290 & $0.278-0.303$ & $<0.001$ & 0.658 & $0.620-0.698$ & $<0.001$ \\
\hline$\geq 80$ & 0.898 & $0.848-0.951$ & $<0.001$ & 0.733 & $0.679-0.793$ & $<0.001$ \\
\hline \multicolumn{7}{|l|}{ Race } \\
\hline White & \multicolumn{2}{|c|}{ Reference } & & \multicolumn{3}{|c|}{ Reference } \\
\hline Black & 3.364 & $3.245-3.487$ & $<0.001$ & 1.585 & $1.500-1.675$ & $<0.001$ \\
\hline Others & 2.808 & $2.708-2.912$ & $<0.001$ & $1.57 \mid$ & $1.484-1.663$ & $<0.001$ \\
\hline \multicolumn{7}{|l|}{ Location } \\
\hline TBPQ & \multicolumn{3}{|c|}{ Reference } & \multicolumn{3}{|c|}{ Reference } \\
\hline TCNP & 5.247 & $5.106-5.393$ & $<0.001$ & 3.903 & $3.687-4.133$ & $<0.001$ \\
\hline \multicolumn{7}{|l|}{ Histology } \\
\hline IDC & \multicolumn{3}{|c|}{ Reference } & \multicolumn{3}{|c|}{ Reference } \\
\hline ILC & 4.612 & $4.446-4.784$ & $<0.001$ & 1.976 & $1.86 \mathrm{I}-2.098$ & $<0.001$ \\
\hline Others & 1.772 & $1.713-1.813$ & $<0.001$ & 1.164 & $1.106-1.225$ & $<0.001$ \\
\hline \multicolumn{7}{|c|}{ Tumor differentiation } \\
\hline I-II & \multicolumn{3}{|c|}{ Reference } & \multicolumn{3}{|c|}{ Reference } \\
\hline III-IV & 2.905 & $2.83 \mathrm{I}-2.982$ & $<0.001$ & 1.145 & $1.097-1.196$ & $<0.001$ \\
\hline \multicolumn{7}{|l|}{ TNM stage } \\
\hline I & \multicolumn{3}{|c|}{ Reference } & \multicolumn{3}{|c|}{ Reference } \\
\hline II-III & 12.086 & II.726-12.457 & $<0.001$ & 191.671 & $175.2 \mid 4-209.674$ & $<0.001$ \\
\hline \multicolumn{7}{|c|}{ Tumor size (mm) } \\
\hline $0-20$ & \multicolumn{3}{|c|}{ Reference } & \multicolumn{3}{|c|}{ Reference } \\
\hline $21-50$ & 3.882 & $3.767-4.001$ & $<0.001$ & 0.057 & $0.052-0.062$ & $<0.001$ \\
\hline$>50$ & 18.943 & $18.150-19.770$ & $<0.001$ & 0.207 & $0.187-0.229$ & $<0.001$ \\
\hline \multicolumn{7}{|c|}{ Breast subtype } \\
\hline HER2-/HR ${ }^{+}$ & \multicolumn{3}{|c|}{ Reference } & \multicolumn{3}{|c|}{ Reference } \\
\hline $\mathrm{HER}^{+} / \mathrm{HR}^{+}$ & 0.376 & $0.369-0.382$ & $<0.001$ & 1.517 & $1.432-1.606$ & $<0.001$ \\
\hline $\mathrm{HER}^{+} / \mathrm{HR}^{-}$ & 0.539 & $0.517-0.563$ & $<0.001$ & 2.688 & $2.479-2.915$ & $<0.001$ \\
\hline Triple-negative & 0.625 & $0.586-0.667$ & $<0.001$ & 0.852 & $0.805-0.902$ & $<0.001$ \\
\hline
\end{tabular}

Abbreviations: BCSS, breast cancer specific survival; HER2, human epidermal growth factor receptor-2; HR, hormone receptor; IDC, invasive ductal carcinoma; ILC, invasive lobular carcinoma; LN, lymph node; OS, overall survival; TBPQ, tumor in the breast peripheral quadrant; TCNP, tumor in the central and nipple portion.

palpable tumors in the central region not only explained the larger tumor size but also explained the increased mortality found in our study.

We elucidated the prognostic value of TCNP in various subgroups of breast cancer patients. Compared with TBPQ, we found that TCNP gave significant poor survival for both BCSS and OS in patients with TNM stage II-III. Furthermore, in the subgroup of $\mathrm{HER} 2^{-} / \mathrm{HR}^{+}, \mathrm{HER}^{+} / \mathrm{HR}^{+}$, and triple-negative cancer, TCNP also gave noticeable prognostic value for predicting poorer BCSS and OS. Therefore, these results provided adequate evidence of decreased survival in patients with TCNP vs TBPQ, particularly for the various kinds of breast cancer subgroups.

This study has some potential implications for clinical practice. In screening, the examination of the axilla for TCNP should be stressed, and MRI may be a more practical imag- ing method for accurate diagnosis. Inevitably, there are also some limitations in the present study. First, SEER, as a large database, may present the risk of coding error, despite its having undergone quality monitoring and integrity evaluation. Second, the subjects with treatment of "no/unknown" radiation or chemotherapy did not necessarily fail to receive these treatments or there may be missing information. Therefore, the SEER did not help to compare the outcomes by treatment received. Furthermore, important variables such as diseasefree survival information are missing from the SEER database. Therefore, studies are needed to further clarify our findings.

\section{Conclusion}

We summarized the clinical characteristics of TCNP and demonstrated that the tumor site of central and nipple position was an independent prognostic factor and had potential impli- 
cations for clinical practice. Patients with TCNP represent a cohort in whom studies of more focused staging procedures are required to assess LN metastases more carefully. Moreover, treatment programs should be studied to determine whether this disease presentation should receive a specifically tailored therapy.

\section{Acknowledgments}

The authors acknowledge the efforts of the Surveillance, Epidemiology, and End Results (SEER) program tumor registries in the creation of the SEER database. This study was supported by grants from Natural Science Foundation of Guangdong Province of China (2017A030313882).

\section{Author contributions}

FJ, W-KX, and C-QY were the main authors of the manuscript. They were involved in the conception, design, and coordination of the study as well as in data analysis, interpretation of results, and drafting the manuscript. $\mathrm{KW}$ was in charge of all experimental procedures. MY, L-LZ, H-FG, Y-FL, TZ, M-YC, W-PL, W-JP, and X-SZ participated in the experimental procedures and revised critically the content of the manuscript. All authors contributed to data analysis, drafting and revising the article, gave final approval of the version to be published, and agree to be accountable for all aspects of the work.

\section{Disclosure}

The authors report no conflicts of interest in this work.

\section{References}

1. Harbeck N, Gnant M. Breast cancer. Lancet. 2017;389(10074):1134-1150.

2. DeSantis CE, Ma J, Goding Sauer A, Newman LA, Jemal A. Breast cancer statistics, 2017, racial disparity in mortality by state. CA Cancer J Clin. 2017;67(6):439-448.

3. Duffy MJ, Harbeck N, Nap M, et al. Clinical use of biomarkers in breast cancer: updated guidelines from the European Group on Tumor Markers (EGTM). Eur J Cancer. 2017;75:284-298.

4. Vila J, Teshome M, Tucker SL, et al. Combining clinical and pathologic staging variables has prognostic value in predicting local-regional recurrence following neoadjuvant chemotherapy for breast cancer. Ann Surg. 2017;265(3):574-580.

5. Nicolini A, Ferrari P, Duffy MJ. Prognostic and predictive biomarkers in breast cancer: past, present and future. Semin Cancer Biol. 2017 (17):30052-30054.

6. Dowsett M, Sestak I, Lopez-Knowles E, et al. Comparison of PAM50 risk of recurrence score with oncotype DX and IHC4 for predicting risk of distant recurrence after endocrine therapy. $J$ Clin Oncol. 2013;31(22):2783-2790.

7. Györffy B, Hatzis C, Sanft T, Hofstatter E, Aktas B, Pusztai L. Multigene prognostic tests in breast cancer: past, present, future. Breast Cancer Res. 2015;17(1):11.

8. Denkert C, Liedtke C, Tutt A, von Minckwitz G. Molecular alterations in triple-negative breast cancer-the road to new treatment strategies. Lancet. 2017;389(10087):2430-2442.
9. Recondo G Jr, de la Vega M, Galanternik F, Díaz-Cantón E, Leone BA, Leone JP. Novel approaches to target HER2-positive breast cancer: trastuzumab emtansine. Cancer Manag Res. 2016;8:57-65.

10. Kroman N, Wohlfahrt J, Mouridsen HT, Melbye M. Influence of tumor location on breast cancer prognosis. Int J Cancer. 2003;105(4):542-545.

11. Sohn VY, Arthurs ZM, Sebesta JA, Brown TA. Primary tumor location impacts breast cancer survival. Am J Surg. 2008;195(5):641-644.

12. Lohrisch C, Jackson J, Jones A, Mates D, Olivotto IA. Relationship between tumor location and relapse in 6,781 women with early invasive breast cancer. J Clin Oncol. 2000;18(15):2828-2835.

13. Sarp S, Fioretta G, Verkooijen HM, et al. Tumor location of the lowerinner quadrant is associated with an impaired survival for women with early-stage breast cancer. Ann Surg Oncol. 2007;14(3):1031-1039.

14. Wu S, Zhou J, Ren Y, et al. Tumor location is a prognostic factor for survival of Chinese women with T1-2N0M0 breast cancer. Int J Surg. 2014;12(5):394-398.

15. Bräutigam E, Track C, Seewald DH, Feichtinger J, Spiegl K, Hammer J. Medial tumor localization in breast cancer - an unappreciated risk factor? Strahlenther Onkol. 2009;185(10):663-668.

16. Hazrah P, Dhir M, Gupta SD, Deo V, Parshad R. Prognostic significance of location of the primary tumor in operable. Indian J Cancer. 2009; 46(2):139-145.

17. Hwang KT, Kim J, Kim EK, et al. Poor prognosis of lower inner quadrant in lymph node-negative breast cancer patients who received no chemotherapy: a study based on Nationwide Korean Breast Cancer Registry Database. Clin Breast Cancer. 2017;17(4):e169-e184.

18. Bevilacqua J, Cody H 3rd, MacDonald KA, Tan LK, Borgen PI, Van Zee KJ. A prospective validated model for predicting axillary node metastases based on 2,000 sentinel node procedures: the role of tumour location. Eur J Surg Oncol. 2002;28(5):490-500.

19. Ansari B, Morton MJ, Adamczyk DL, et al. Distance of breast cancer from the skin and nipple impacts axillary nodal metastases. Ann Surg Oncol. 2011;18(11):3174-3180.

20. Lewis EI, Ozonoff A, Nguyen CP, Kim M, Slanetz PJ. Breast cancer close to the nipple: does this increase the risk of nodal metastasis at diagnosis? Can Assoc Radiol J. 2011;62(3):209-214.

21. Sobin LH, Gospodarowicz MK, Wittekind C. TNM Classification of Malignant Tumours. John Wiley \& Sons; New Jersey. 2011.

22. Wu SG, Zhang WW, Sun JY, Li FY, Chen YX, He ZY. Postoperative radiotherapy for invasive micropapillary carcinoma of the breast: an analysis of surveillance, epidemiology, and end results database. Cancer Manag Res. 2017;9:453-459.

23. Elston CW, Ellis IO. Pathological prognostic factors in breast cancer. I. The value of histological grade in breast cancer: experience from a large study with long-term follow-up. Histopathology. 1991;19(5):403-410.

24. Wu SG, Zhang WW, Sun JY, He ZY. Prognostic value of ductal carcinoma in situ component in invasive ductal carcinoma of the breast: a surveillance, epidemiology, and end results database analysis. Cancer Manag Res. 2018;10:527-534.

25. Gou ZC, Liu XY, Xiao Y, Zhao S, Jiang YZ, Shao ZM. Decreased survival in patients with carcinoma of axillary tail versus upper outer quadrant breast cancers: a SEER population-based study. Cancer Manag Res. 2018;10:1133-1141.

26. Hammond ME, Hayes DF, Dowsett M, et al. American Society of Clinical Oncology/College of American Pathologists guideline recommendations for immunohistochemical testing of estrogen and progesterone receptors in breast cancer. J Clin Oncol. 2010;28(16):2784-2795.

27. Mendelson EB, Böhm-Vélez M, Berg WA, et al. Breast Imaging Reporting and Data System, BI-RADS - Ultrasound. 2nd ed. Reston, VA: Am Coll Radiol; 2013

28. Ferré R, Alsharif S, Paré M, Kao E, Mesurolle B. Should the axilla be included in screening us? Radiology. 2015;274(2):623-624.

29. Rummel S, Hueman MT, Costantino N, Shriver CD, Ellsworth RE. Tumour location within the breast: does tumour site have prognostic ability? Ecancermedicalscience. 2015;9:552. 
Cancer Management and Research

\section{Publish your work in this journal}

Cancer Management and Research is an international, peer-reviewed open access journal focusing on cancer research and the optimal use of preventative and integrated treatment interventions to achieve improved outcomes, enhanced survival and quality of life for the cancer patient.

The manuscript management system is completely online and includes

Submit your manuscript here: https://www.dovepress.com/cancer-management-and-research-journal

a very quick and fair peer-review system, which is all easy to use. Visit $\mathrm{http}: / / \mathrm{www}$.dovepress.com/testimonials.php to read real quotes from published authors. 